\title{
Pedagogia performativa e seus não-lugares: reverberações da khôra a partir de Platão, Derrida e Agamben
}

\section{Performative pedagogy and its non-places: reverberations of khôra based on Plato, Derrida and Agamben}

\author{
Marcelo de Andrade Pereira* \\ Gilberto Icle**
}

\begin{abstract}
RESUMO
A presente investigação, de teor ensaístico, discorre sobre as reverberações discursivas (de maior expressão filosófica) da figura-conceito khôra, apontando para as injunções pedagógico-performativas e suas variáveis ético-políticas. O texto indaga, pautado pelas elaborações de Platão, Jacques Derrida e Giorgio Agamben, sobre a noção de lugar (e não-lugar) condensada em khôra, tendo em vista aflutuação da posição de/do sujeito - dos lugares que ocupa, engendra e com os quais (se)identifica - na constituição de um comum - espaço em que o próprio e o impróprio poderiam coabitar. $\mathrm{Na}$ contramão de uma interpretação que concebe a pedagogia performativa ora como poética e ora como instauradora de um entrelugar, este texto sinaliza para a condição de im-potênciae in-determinação intrínsecas da mesma, demonstrando seu caráter des-criativo, aberto e contingencial.

Palavras-chave: Pedagogia Performativa. Des-criação. Comum. Espaço. khôra.
\end{abstract}

* Universidade Federal de Santa Maria, Centro de Educação, Programa de Pós-Graduação em Educação. Santa Maria, Rio Grande do Sul, Brasil. E-mail: marcelo.pereira@ufsm.br. http:// orcid.org/0000-0003-1180-1156

** Universidade Federal do Rio Grande do Sul, Faculdade de Educação, Programa de Pós-Graduação em Educação. Porto Alegre, Rio Grande do Sul, Brasil. E-mail: gilbertoicle@gmail. com. http://orcid.org/0000-0001-7961-4782 


\begin{abstract}
This essay-like research deals with the discursive reverberations (of greater philosophical expression) of the concept figure khôra, pointing to pedagogical-performative injunctions and their ethical and political variables. Based on the elaborations of Plato, Jacques Derrida and Giorgio Agamben, the text investigates the notion of place (and non-place) condensed in khora, in view of the subjects's fluctuating position - of the places he occupies, engenders and with which he identifies - in the constitution of a common place - a space in which the personal and the impersonal could coexist. Contrary to an interpretation that conceives performative pedagogy as a poetics and establisher of an interplace, this text signals to the condition of impotency and indeterminacy intrinsic to this performative pedagogy, demonstrating its un-creative, open and contingent character.
\end{abstract}

Keywords: Performative pedagogy. Un-creation. Common place. Space. Khôra.

To fill a Gap

Insert the Thing that caused itBlock it up

With Other - and 'twill yawn the moreYou cannot solder an Abyss

With Air. ${ }^{1}$

\title{
Emily Dickinson
}

Com a voz entrecortada respondia: nesse espaço não se dará azo e nem lugar àquilo-àquele que intente apagar aquele-aquilo para o qual não há lugar. Acede o grupo, não todo; dele, um escapa; e no encalço a porta sela. Uma situação embaraçosa antecedia a enfática afirmação - e, por conseguinte, a fuga que ela provocava -, instalando uma atmosfera indefinível, volátil, outra. Em off, o

1 Uma série de dificuldades se interpõe à tradução do poema - e de todo e qualquer poema que seja "estrangeiro" à língua da/na qual se origina. No espectro semântico da palavra inglesa gap são comportadas na tradução para a língua portuguesa, as noções de vazio, hiato, intervalo. Todavia, como logo constataremos, khôra - figura central desse estudo - não constitui e sequer pode constituir um espaço vazio; esse "vazio" in-tradutório aparece então aqui como sua não negação, de maneira a assinalar, desde o princípio, a im-possibilidade de preenchimento ou mesmo atenuamento da hiância - objeto indireto da investigação - na epígrafe antecipada. Em tempo, os autores gostariam de agradecer à inestimável e contínua interlocução da professora Simone Zanon Moschen, do Instituto de Psicologia, da Universidade Federal do Rio Grande do Sul, com a qual têm se compartilhado ao longo de muitos anos um conjunto significativo de inquietações - esse texto é parte desse conjunto. 
estudante reprocha o professor: haveria, pois, uma problemática e im-própria metodologia em curso. As modulações de voz, o timbre estridente, os gestos amorfos, flutuantes seriam traços, marcas indiciárias de uma forma de vida cuja natureza seria questionável, não podendo ser tomada como algo propriamente "saudável". A censura buscava, por certo, inibir não apenas a presença como também a tentativa de evidenciamento de uma espécie de identidade ali não nomeada, "opaca", "periférica", a qual poderia ensejar, para o admoestador, uma ainda maior e preocupante e indevida aderência.

Ao lançar mão de um relato, conciso e emblemático, o presente ensaio pretende estirar um conjunto de aspectos não plenamente desenvolvidos no âmbito da pesquisa sobre a performance na educação e, em particular, no da pedagogia performativa. Essa intervenção teórica parte do postulado que a predicação de entrelugar - geralmente utilizada para definir o espaço criado pela ação pedagógica em performance - não esgota a discussão acerca do caráter trans e multidimensional do espaço pedagógico performativo; ${ }^{2}$ assim sendo, pensa-se aqui esse espaço à maneira de khôra. A substituição da noção de entrelugar pela última, procura, não obstante, explicitar a condição de fértil indefinição e desmanche do dado que caracterizaria a proposta de uma pedagogia performativa. Não se trata, pois, de um entrelugar, mas de um lugar - aberto e sem fundo - sem lugar, para aquilo o que não tem lugar.

Nesse espaço de performance e, também, performativo, o lugar é concebido desde o ponto de vista do plural, do heterogêneo e da in-diferença (HANNAH, 2011, p. 55); em khôra, esses tópicos são como que englobados pela mesma, visto que abre a senda por meio da qual se faz possível avizinhar-se do não integrável - seja por sua "natureza" indefinida e mesmo im-própria.

Mutatis mutandi, intenta-se, nesse estudo, repensar o que em nossa produção se tem caracterizado como pedagogia performativa. A emergência das relações entre Performance e Educação, inauguradas por nós na pesquisa em Educação (ICLE, 2010; PEREIRA, 2010), em âmbito nacional, permitiram desenvolver algumas ferramentas metodológicas para melhor compreendermos o que sabemos sobre Pedagogia. Assim, nesses trabalhos (e em outros) temos desenvolvido a noção de pedagogia performativa. Esse ensaio constitui, por

2 Um estudo impulsionador sobre esse tema foi recentemente publicado pelo Caderno CEDES; referimo-nos ao artigo de Gilberto Icle e Mônica Bonatto (2017) intitulado Por uma Pedagogia Performativa: a escola como entrelugar para professores-performers e estudantes-performers. Essa investigação procura, à diferença daquela, demonstrar que a noção de entrelugar - baseada na ideia de limiar -, caracteriza apenas uma faceta do espaço pedagógico performativo; partimos do pressuposto, aqui, de que a figura-conceito khôra é capaz de amplificar esse entendimento, pretendendo além do mais manter o caráter aberto, indefinido e de inscrição do espaço pedagógico em questão. 
sua vez, um último esforço de ampliar, atualizar e reconfigurar o entendimento dessa, por meio do exame da figura-conceito khôra. Vejamos.

De intrincada argumentação, o Timeu, de Platão, apresenta-se como o diálogo em que figura de maneira categórica sua cosmogonia; nela, o filósofo realiza uma minuciosa descrição do processo por intermédio do qual teria sido o mundo (kosmos) criado. Seu modelo explicativo reconhece, com efeito, a existência de uma causa demiúrgica - divina, porém, não necessariamente primeira - a qual, por meio de dois modelos ou arquétipos, um idêntico a si mesmo e imutável e, outro, ao vir a ser -, teria sido responsável pela fabricação de tudo o que há no mundo, feitos à imagem do ser-desde e para sempre uniforme. $\mathrm{O}$ cosmos pertenceria, nesse esquema, à ordem do devir, ainda que construído com base em um esforço de intelecção do modelo ideal; "é visível e tangível e tem corpo, assumindo todas as propriedades do que é sensível" [29a] (PLATÃO, 2011, p. 95).

Essa breve consideração acerca do texto platônico torna evidente a existência de dois planos ou níveis ontológicos - o do inteligível e o do sensível -, os quais engendrariam formas de "cognição" correlatas. Como esclarece Platão, o plano do inteligível é passível de ser "apreendido pelo pensamento com o auxílio da razão", visto que imutável, ao passo que o plano do sensível, é "objeto de opinião acompanhada da irracionalidade dos sentidos”[28a] (PLATÃO, 2011, p. 93-94).O tracejamento desses diferentes registros leva, notadamente, à diferenciação e à hierarquização de formas de saber: de um lado, o resultado de um processo de intelecção, a epistêmê e, de outro, o produto de uma relação indiscriminada com o sensível, a doxa.

A rigor, o único saber legítimo que se pode depreender do sensível se trata, nessa vertente, de um discurso sobre o mesmo [37b, 37c] (PLATÃO, 2011, p. 108-9). E é justamente desde essa ordenação lógica plasmada em discurso - e não na sensibilidade - que Platão aventa o deslinde de uma sorte de conhecimento superior, verdadeiro, mais estável e invariável; todavia, o mundo só pode ser conhecido, pelo humano, por meio de sua própria materialidade. A afirmação soaria equivocada - tendo em vista a reiteração sovada das dicotomias estruturais de Platão no pensamento ocidental -, podendo inclusive tornar infrutífera toda e qualquer tentativa de apreensão do verdadeiro - no âmbito dessa fórmula -, caso a operação intelectiva humana não se assemelhasse àquela que representaria, no enredo do filósofo ateniense, a própria intelecção: Demiurgo, a mais bela, boa, justa e divina entidade, o artífice que cria o mundo sensível por meio da imitação do modelo ideal [29a, 29b] (PLATÃO, 2011, p. 95-6).

A discussão acerca dos postulados onto-epistemológicos de Platão não é, certamente, aleatória; ela busca, de fato, demonstrar os princípios em que se funda um terceiro nível ontológico - cerne desta intervenção teórica - presente 
no que se poderia chamar de intervalo, gap ou hiância entre o inteligível e o sensível, remetendo a um registro outro, distinto dos mesmos; esse espaço é designado pelo mestre de Aristóteles como sendo o da khôra.

Grosso modo, Khôra aponta para uma instância intermediária - não necessariamente liminar ${ }^{3}$ - que apresenta uma condição discursiva ainda mais complexa que a do plano inteligível e a do plano sensível. De "difícil" e "obscura" definição [48a] (PLATÃO, 2011, p.131), khôra não só "não admite destruição" como "providencia uma localização a tudo quanto pertence ao devir", sendo acessível apenas por um "certo raciocínio bastardo, sem recurso aos sentidos" [52b] (PLATÃO, 2011, p. 138). "Invisível e amorfa, que tudo recebe", khôra" participa do inteligível de um modo imperscrutável e difícil de compreender" [51b] (PLATÃO, 2011, p. 135); tal dificuldade se deve, em parte, ao extenso conjunto terminológico utilizado por Platão para denominá-la. Nele, o filósofo refere ora "local" [52a], "localização" [52b], ora "receptáculo" [49a], ora "um aquilo em que" [49e], ora "suporte de impressão para todas as coisas, sendo alterado e moldado pelo que lá entra" [50c] (PLATÃO, 2011, p. 131-138); a significação de khôra se torna ainda mais abrangente a partir do momento em que Platão a toma analogicamente por "mãe" [50d] e "ama" [49a] (PLATÃO, 2011, p. 131-134). ${ }^{4}$

3 Embora semelhante à khôra, o limiar dela se distingue; referências topo-simbólicas, khôra e limiar respondem cada uma a zonas distintas de in-diferenciação; o limiar, contudo, refere mais uma zona transicional (de passagem), flutuante e de mudança, do que propriamente uma zona de inscrição não diferencial - tal como se poderá observar acerca de khôra. O limiar se relaciona, além do mais, com um elemento que não se apresenta em khôra, o ritual - porquanto constitua um espaço-tempo de transformação qualitativa. Ainda que, por força étima, limite se aproxime de limiar - derivação de limes que, na antiguidade romana, designava as fronteiras do Império -, o limiar com o limite não coincide, visto que limite designa fronteira, ao passo que limiar refere zona; a definição desses termos em muito se inspira nas formulações de Walter Benjamin, para quem tanto o método quanto a infância e as passagens parisienses - para citar alguns de seus objetos - constituem zonas limiares, de passagem e indiferenciação (BENJAMIN, 1984; 1987; 2002). O entendimento de Giorgio Agamben acerca do limiar, tal como expresso em sua Comunidade que vem, é relativamente distinto desse; para Agamben, o limiar não é "uma outra coisa em relação ao limite; ele é por assim dizer, a experiência do limite mesmo, o ser-dentro de um fora" (2013a, p. 64). Seja como for, análises detidas e consistentes sobre essas noções podem ser encontradas nas obras Limiares sobre Walter Benjamin, de João Barrento (2013), Limiar, aura e rememoração, de Jeanne Marie Gagnebin (2014) e na coletânea organizada por Georg Otte, Sabrina Sedlmayer e Elcio Cornelsen intitulada Limiares e Passagens em Walter Benjamin (2010). Pode-se mencionar ainda o artigo intitulado Pedagogia da Performance: do uso poético da palavra na prática educativa (PEREIRA, 2010), o qual fornece um nexo objetivo do limiar com a pedagogia performativa; além, é claro, do artigo já mencionado de Icle e Bonatto (2017).

4 A interpretação efetuada por Jacques Derrida (1995) da noção de khôra, em seu texto homônimo, explora exatamente essas analogias, destacando o caráter ético e político implícito na instância em questão, desde uma abordagem linguística; sobre isso discorreremos adiante. 
Rodolfo Lopes, em seu comentário ao diálogo em questão, sublinha que o drapejar desses termos impossibilita indicar onde precisamente khôra se situa. Ele observa, contudo, que essas noções sinalizam invariavelmente para a dimensão espacial da mesma; de constituição ontológica híbrida, khôra designa tanto uma "extensão ou espaço como condição de localização" como e, ao mesmo tempo, o "próprio local ocupado por um corpo", a realização da própria extensão (LOPES, 2011, p. 44).

Isso posto, não seria errôneo afirmar que, em Platão, não se faz possível definir o que khôra é, mas tão só interpretar o que por ela se interpreta, "perceber", por assim dizer, suas reverberações discursivas. Essa intuição instala, como poderemos averiguar, uma dimensão política não explícita, muito embora, pressuposta, neste diálogo. ${ }^{5}$ É interessante assinalar, em tempo, que no preâmbulo de Timeu Platão remonta à República, de modo a recuperar alguns elementos dessa mesma obra, corolária da especulação sobre as instituições do Estado Ideal e suas respectivas funções, entre as quais, a definição das atribuições e lugares dos indivíduos no âmbito da pólis, do comum. ${ }^{6}$

Embora o aspecto político ressoe no Timeu, não se pode afirmar que ele ali componha um tópico central de discussão (não sendo seu objeto, mas o pano de fundo). Isso não invalida, contudo, as inúmeras tentativas de resgate desse enlace ao longo do texto. Dentre as mais diversificadas leituras que exploram o substrato político "implícito" no texto de Platão encontramos o robusto e sinuoso exame do termo khôra, de viés linguístico, de Jacques Derrida (1995) - o qual, como se observará, colocará em xeque - quer negando, quer suspendendo - as significações atribuídas/depreendidas de khôra sob a lente de Platão. A empreitada de Derrida baseia-se, com efeito, numa primeira e deliberada operação hermenêutica cujo anelo consiste no deslocamento do esquema do clássico pensador, inicialmente relacionado com níveis ontológicos (gêneros de entes), para o âmbito do discurso, sinalizando, por sua vez, uma terceira via, qualitativamente distinta do mito e do logos - assentados, respectivamente, no sensível e no inteligível; para o pensador francês, esse terceiro gênero forneceria um ponto de sutura e superação - paradoxalmente, de clivagem e alargamento - tanto de uma lógica binária quanto de uma lógica da não contradição; pois, a

5 Como bem nos lembra Bini (2010, p. 11), esse diálogo de Platão tem um caráter fundamentalmente teológico, não configurando uma obra política propriamente dita, muito embora a essa dimensão aduza.

6 A discussão concernente ao atravessamento político da khôra será, como veremos, retomada por Derrida (1995). Outra reflexão, tão refinada e aprofundada quanto a do filósofo desconstrutivista, pode ser encontrada n'A Partilha do Sensivel, de Jacques Ranciére (2005). Nesse estudo, Rancière busca explicitar o laço que une a estética à política, recorrendo ao contexto da organização social ateniense para demonstrar os regimes de visibilidade - estética e ética - vigentes. 
khôra excede essas polarizações, inquietando "a própria ordem da polaridade, da polaridade em geral, quer ela seja dialética ou não" (DERRIDA, 1995, p. 16).

$\mathrm{Na}$ esteira desse entendimento, infere-se que (o pensamento da/sobre) khôra não pertence ao "horizonte do sentido", pois seria irredutível ao próprio nome, de maneira a demonstrar a tibieza, a contingência e a provisoriedade contidas em sua inevitável designação (DERRIDA, 1995, p. 17); essa afirmação reforça a percepção de Derrida acerca de um suposto limite antropomórfico apresentado por Platão em sua concepção de khôra, no qual essa figura como receptáculo, suporte ou mesmo lugar - que receberia e daria lugar ao ente. As analogias parentais utilizadas pelo filósofo ateniense, como "mãe" e "ama", realçam justamente essas ideias. Porquanto esses epítetos não refiram uma essência, um ser propriamente estável, seria problemático supor que khôra, dentro dessa notação conceitual, pudesse receber ou dar lugar a qualquer coisa que fosse, pois, a khôra não é, não se circunscreve por nenhum gênero conhecido ou mesmo reconhecido; ela não é geratriz, nem não é. ${ }^{7}$

"Khôra não deve receber para si, não deve, pois, receber, somente se deixar emprestar as propriedades (daquilo que recebe). Ela não deve receber, ela deve não receber aquilo que ela recebe" (DERRIDA, 1995, p. 23). A invocação de Derrida de uma singular im-propriedade da khôra revela, pois, uma condição de absoluta in-determinação. De acordo com ele, khôra remete a algo mais situante do que propriamente situável (DERRIDA, 1995, p. 15), algo que, ainda que não seja tomado como sujeito ou substrato, leva a uma espécie de ex-propriação, "lugar em que a lei do próprio não tem mais nenhum sentido" (DERRIDA, 1995, p. 36).

A fim de melhor aproximar-se e escandir a significação de khôra, reconhecidamente refratária a qualquer intento de fixação, Derrida se reportará a um recurso especular literário - tomado também sob sua forma metafórica - que, ao mesmo tempo em que preserva a incomensurabilidade e indecibilidade de khôra, permite recolocar o problema disparado pelo sábio no campo da política, trata-se da mise en abyme. ${ }^{8}$

7 No contexto da teoria de Giorgio Agamben (2015a; 2015b) essa noção repicará, aparentemente, em seu conceito de potência de não - formulação que o filósofo italiano toma emprestado da teoria de ato e potência, de Aristóteles; Bartleby representa, assim, no texto homônimo de Agamben, o grau máximo da im-potência, da potência de não, da potência em ato; é precisamente dessa potência de não que subjaz aqui aquilo que se entende por des-criação.

8 Mise en abyme (relato em abismo ou narrativa espelhada) refere-se a um recurso de autorre-ferencialidade e rearticulação crítica textual; possibilita reproduzir em um fragmento a totalidade de um texto, sua inteireza (DÄLLENBACH, 1977). Sob sua forma metafórica, a khôra pode significar "um movimento de cratera sem fundo, de sorvedouro abissal, de um abismo dentro de outro que regularia o discurso" sobre a mesma (BONATTI in DERRIDA, 1995, p. 32). Mise en abyme designa, ainda, uma espécie de repetição infinita e vertiginosa; por exemplo, a imagem refletida em um espelho à frente de outro espelho. 
"Mise en abyme do discurso sobre khôra, lugar da política, política dos lugares, tal seria, pois, a estrutura de uma sobreimpressão sem fundo" (DERRIDA, 1995, p. 35). A articulação estabelecida por Derrida com a dimensão do comum e do plural não se restringe, por certo, à remissão preambular de Platão aos conteúdos sociorganizacionais expressos na República (tal como já se observou), visto que procura restituir àquela movediça posição dos interlocutores, no contexto do drama, sua real significação; a política atravessa, permeia o diálogo.

Curiosa e ironicamente, Sócrates não figura no Timeu como o protagonista da trama; ele é, pois, destituído do lugar que habitualmente ocupa nos escritos de Platão e seu autoapagamento é deveras significativo, uma vez que com ele se apaga, de modo colateral, gêneros de todos os tipos e todos os tipos de gêneros; ele se situa ou mesmo se institui, na ótica de Derrida, em "destinatário receptivo, [...] em receptáculo, de tudo aquilo que vai doravante se inscrever" (DERRIDA, 1995, p. 43). Numa bela passagem de seu texto, Derrida assim o descreve:

Sócrates não é khôra, mas se lhe pareceria bastante se ela fosse alguém ou alguma coisa. Em todo caso, ele se põe em seu lugar, que não é um lugar dentre outros, mas talvez o próprio lugar, o insubstituível lugar, do qual ele recebe a palavra daqueles diante dos quais se apaga, mas que a recebem também dele, pois ele as faz falar; e nós também, implacavelmente (DERRIDA, 1995, p. 45).

Uma vez nomeado "destinatário receptivo", Sócrates in-forma, dentro dessa perspectiva, matéria de khôra, ocupando e dando lugar, como ouvinte, a todas as narrativas - obviamente, daquilo que lhe foi dirigido. ${ }^{9}$ Ora, embora sejam essas narrativas ali ouvidas, elas não chegam, nesse lugar, a configurar uma, a se perpetuarem. A torção semântica do termo em e como escuta-implícita na posição socrática do ouvinte -, torna ainda mais evidente o estatuto político peculiar de khôra, porquanto opere, tanto como espaço de escuta quanto o de fala,

9 Como acertadamente salienta Lopes (2011, p. 47), a correlação entre khôra e hylê (matéria), não encontra respaldo no texto platônico; ela parte, de fato, da leitura realizada por Aristóteles como aparece em sua Física -, do primeiro termo; sendo, por sua vez, replicada nas formulações de Derrida e Agamben. Nesse mesmo diapasão, Attell (2015, p. 114) aponta para a necessidade de não reduzir o conceito de matéria aventado por Aristóteles, relido e rebatido por Derrida e Agamben, à sua dimensão meramente física, porquanto a hylê seja compreendida também como potência; a matéria não é a consumação da potência $n o$ ato, sua finalização, mas a própria potência $\mathrm{em}$ ato; esse ponto recebe especial atenção de Agamben em seu livro A Ideia da Prosa (2013b), no fragmento intitulado ideia de matéria; assim como em sua concepção (neo)aristotélica de im(potência) (AGAMBEN, 2015a; 2015b, entre outros). 
diferenciando-se, não obstante, do lugar inicialmente reservado, pelos gregos (de onde parte toda essa construção conceitual) para isso, qual seja, o espaço da ágora; em se tratando, pois, de um lugar de ocupação, torna-se impreciso afirmar que khorra constitua um espaço propriamente vazio (DERRIDA, 1995, p. 41-42).

Em todo caso, vale ressaltar que a série de analogias evocadas por Platão - em relação a khôra - na qual se inscrevem aquelas já salientadas: "mãe", "ama", "receptáculo" -, apesar de retida por Derrida é, no mesmo momento, por ele refutada; com isso, Derrida procura demonstrar a intrínseca inadequação nominal de khôra; em sua notação conceitual, o nome não alcança khôra; todavia, é apenas por intermédio dele que essa pode se dar a ver, refletir, ser refletida, especular ao ser especulada, rebater sua fonte; ela consiste numa figura retórica que procura restituir ao nome sua radical anonimidade; como já o dissemos, o nome não designa uma palavra, tampouco um conceito, sendo justamente essa qualidade de khôra que Derrida decanta em sua exposição. ${ }^{10}$

Uma "formulação"de khôra similar à de Derrida - e muito provavelmente dele derivada (ATTELL, 2015, p. 108) -, é oportunamente apresentada pelo filósofo italiano Giorgio Agamben; nele, porém, a noção de khôra encontra-se como que criptografada, diluída e pulverizada ao longo de toda a sua obra, não se circunscrevendo precisamente num ou noutro texto. Como baixo contínuo, khôra adensa, sub-repticiamente, a maior parte das noções agambenianas plasmadas em sua Comunidade que vem; desde, a de qualquer como as de exemplo, limbo, manêrie, demoníaco, pseudônimo - e, por aí em diante (AGAMBEN, 2013a); todos esses termos - e seus congenêres - referem-se, no conjunto da obra do filósofo, a uma zona de indeterminação em que o existente poderia, de fato, existir. ${ }^{11}$

Em sua Comunidade que vem, Agamben se reporta diretamente à khôra, tomando-a como o locus propício, possível para "uma apropriação da impropriedade como tal" (AGAMBEN, 2013a, p. 22). Essa definição, entretanto, não se

10 Attell (2015, p. 114) assinala que em Derrida khôra se apresenta como sinônimo e mesmo pseudônimo do conceito de differánce. A investigação que aqui se realiza não endossa essa afirmação, pois supõe que o exame dessa correlação requer um estudo específico e aprofundado - o qual não é aqui efetuado; é interessante, contudo, apontar para essa possibilidade em vista de futuras intervenções.

11 Na coletânea brasileira crítico-interpretativa da obra $A$ comunidade que vem, de Agamben, organizada por Sedlmayer, Guimarães e Otte (2007), e intitulada $O$ comum e a experiência da linguagem -, Antelo (2007, p. 29) nos lembra que o termo que vem presente no título daquele texto, não se refere ao por vir, mas, de fato, àquilo que é inoperante e decreativo, "que está sempre chegando no meio de uma coletividade e é justamente porque nunca acaba de chegar, que ela resiste ao coletivo e até mesmo ao indivíduo. Chega ao limite: mais ainda, ela é o limite que se de-limita". Salienta-se, ademais, que o capítulo ter lugar, da Comunidade (2013a) faz igualmente uma remissão direta a esse problema. 
confunde e muito menos se restringe àquela oferecida por Derrida, para quem o termo designaria um espaço de "sobreimpressão sem fundo" (DERRIDA, 1995, p. 35); com a tenacidade que lhe é peculiar, Agamben se distancia da pergunta pelo elemento nominal de khôra- cerne da empreitada derridadiana - para se concentrarem sua dimensão ética; para ele, interessa menos saber o que esse algo é e, mais, o que nele pode ter lugar.

A fim de demonstrar o amplo espectro do termo, Agamben recupera a relação de khôra com a verdade e com o bem - termos que subjazem à formulação de Platão, explicando, além do mais, a razão pela qual no filósofo italiano o espaço de khôra figure em sua relação com a teologia. Todavia, diferentemente de Platão, Agamben esgarça, esboroa os limites de khôra, de modo a nela recolocar o problema da ética; diz ele

A ética começa somente lá onde o bem se revela não consistir em outra coisa senão uma apreensão do mal, e o autêntico e o próprio, não ter outro conteúdo senão o inautêntico e o impróprio. É este o sentido do antigo adágio filosófico segundo o qual veritas patefacit se ipsam et falsum. A verdade não pode manifestar a si mesma senão manifestando o falso, o qual não é separado e rechaçado em um outro lugar; ao contrário, segundo o significado etimológico do verbo patefacere, que equivale a "abrir" e é conexo a spatium, a verdade se manifesta somente dando lugar à não-verdade, isto é, como ter-lugar do falso, como exposição da própria e íntima impropriedade. (AGAMBEN, 2013a, p. 21) ) $^{12}$

Apesar de Agamben abordar khôra de maneira transversal - porquanto de fato ele não a conceitue -, suas considerações permitem pensar um lugar no qual haveria de se estabelecer uma comunidade "sem pressupostos e sem sujeitos" - um comum de "quaisquer", locus de inscrição do que está fora, do que é impróprio e inautêntico -, que acolheria e em que se exporia, tornando visível, uma singularidade comum, inessencial, sem identidade ou pertencimento, nem assim (ou assado), mas o próprio assim (AGAMBEN, 2013a, p. 61).

Esse lugar constitui um espaço ventricular do "Mais Comum, que elimina toda comunidade real", expropriando "todas as identidades para apropriar-se do

12 A concepção agambeniana de verdade está, como nos faz notar o tradutor de $A$ comunidade que vem (AGAMBEN, 2013a), diretamente atrelada a de Martin Heidegger, o qual compreeende alétheia como tudo aquilo que se manifesta. O livro Les maîtres de vérité dans la Grèce archaïque, de Marcel Detienne (2006) é, nesse sentido, esclarecedor. Nele, Detienne infere que a ideia de verdade no ocidente não passa senão de uma modulação histórica e semântica do termo grego alétheia. 
pertencimento mesmo" (AGAMBEN, 2013a, p. 18-19). Dito de outro modo, para Agamben, em sua relação com o comum, o qualquer, a singularidade etc., khôra pode configurar uma zona de indeterminação comunicacional que aloja o incomunicável, ou seja, em que o que se pode comunicar é tão somente a própria incomunicabilidade; essas intuições permitem, pois justificar a discussão sobre o sentido da ética no pensamento de Agamben, uma vez que não se trata de definir um espaço em que o singular seja de fato reconhecido, mas, antes e ao contrário, de reconhecimento da impossibilidade do próprio re-conhecer.

Doravante, tendo sido realizada essa árida e limitada exposição das reverberações de khôra nos pensamentos de Platão, Derrida e Agamben, passemos agora às suas injunções pedagógico-performativas.

Vago, impreciso e nebuloso, assim é - e, a rigor, assim deveria sê-lo - o relato com o qual se iniciou o presente ensaio; nele, procura se tornar manifesta uma singularidade de igual predicação - sem fundo e contingencial -, um aquilo que vem, que está aí, que possui uma materialidade, uma presença. ${ }^{13}$ Com ele, pretendeu-se, aqui, apenas demonstrar no âmbito da pedagogia performativa ${ }^{14}$ a possibilidade de criação de um espaço multidimensional de sentidos - sejam eles da ordem da sensibilidade, de orientação geográfica ou da linguagem -, isto é, de presentificação de "modos de dar-se a ver (ou representar) no tecido social", atualizando, por conseguinte, os laços que vinculariam uma singularidade a outra na esfera do comum (PEREIRA, 2013, p. 31).

Essa atualização não se efetiva certamente na ideia de subsunção, de absorção do outro pelo mesmo, de sua "benévola" e "não dissimulada" tolerância, do re-conhecer de um pelo outro. ${ }^{15}$ Não se trata, com efeito, de uma tentativa de pareamento das subjetividades - pois, sequer se pode pressupor que essas constituam singularidades e que componham de fato um comum; ao que tudo indica, não.

Como vimos, o relato introdutório aponta diretamente para esse lacuna relacional; de igual modo, exemplos abundam no registro da realidade político-social brasileira, permitindo corroborar essa afirmação, quais sejam: o encerra-

13 No mesmo diapasão teórico, relaciona-se à pedagogia performativa aquilo que chamamos Estudos da Presença (ICLE, 2011), um conjunto de investigações que visam problematizar os limites da linguagem na produção em arte, na educação e na cultura.

14 A noção de performance - implícita na de pedagogia performativa - compreende, aqui, as três dimensões por intermédio das quais a mesma é perguntada: arte, cultura e linguagem. Uma investigação detalhada das múltiplas significações de performance, face ao campo da educação, foi realizada por um de nós, como consta no artigo Performance e Educação: relações, significados e contextos de investigação (PEREIRA, 2012).

15 Em certa medida, a ideia de re-conhecimento implica uma posição referencial, o estabelecimento de parâmetros a partir dos quais um outro poderia ser re-conhecido. A figura de khôra apresenta-se, portanto, como uma possibilidade reflexiva de um lugar em que o caráter de intangibilidade e indecibilidade do outro seja de fato preservado. 
mento da exposição Queermuseu, em agosto de 2017, na cidade de Porto Alegre; o crescente número de assassinatos de LGBTTTs (lésbicas, gays, bissexuais, travestis, transexuais e transgêneros), a estarrecedora revogação de direitos das assim chamadas minorias (pretos, pobres, mulheres, portadores de deficiência), o movimento Escola sem partido, o vertiginoso avanço e defesa de pautas político-religiosas em esferas público-decisórias, a exacerbação de humores na apresentação de posições (político-partidárias, ideológicas e mesmo epistemológicas) contrárias às predominantes - abolindo, inclusive, a possibilidade do próprio diálogo - e a paulatina interdição da livre expressão do pensamento.

Esse quadro desalentador revela, indubitavelmente, o ressurgimento de uma estrutura típica de Estados Totalitários, cuja realização só pode ser levada a termo pela destruição política da vida pública, pelo isolamento e despotencialização dos sujeitos, pelo tamponamento das suas faculdades expressivas e, por conseguinte, pela aniquilação de toda e qualquer singularidade, a qual tem por finalidade a instauração e manutenção de uma ordem tirânica e cabal (ARENDT, 1989); ${ }^{16}$ aparentemente, isso não está longe de se consumar - o que torna ainda mais clara a necessidade e a urgência de invenção e inventariamento de novos arranjos sociais; a pedagogia performativa constitui, por sua vez, um ponto de sustentação e transformação desses existentes.

Pode-se dizer, então, a despeito de eventuais e quaisquer filiações ideológicas, que todas essas forças beligerantes tencionam assegurar uma maior participação de um contingente dito apartado histórica e politicamente do âmbito do comum; todas elas, sem exceção, procuram dar visibilidade a formas de vida que não pertenceriam ao quadro de uma tipologia subjetiva totalizante. ${ }^{17}$

Como sendo uma "metodologia crítica", assim como "uma "modalidade de exposição', de irrupção do qualquer", a pedagogia performativa fixa no bascular dessas operações - metodológica e estética - "um ponto por intermédio do qual se torna possível um salto imaginativo dentro de 'outros modos de

16 O sentido de singularidade não se confunde com o de conjunto ou mesmo com o de comum, ao menos não nos termos com os quais tem-se tentado compreender a instauração de uma comunidade pura inessencial, desde obviamente o esquema agambeniano; de qualquer modo, ao mencionarmos grupos particulares procura-se apenas tornar nítido um primeiro grau de tensões intrínsecas no jogo político das in-visibilidades e inscrições. A questão da singularidade com o conjunto, pode melhor ser averiguada no item principium individuationis, da Comunidade (AGAMBEN, 2013a, p. 25-28).

17 Uma vertente expressiva dos estudos da performance na Educação busca debruçar-se sobre essas questões - étnico-raciais, de gênero, nacionais etc. Destacam-se, pois, os estudos de Warren (2005), Baszille (2005), Aleman (2005), Urrieta Júnior. (2005), Alexander (2013), Gingrich-Philbrook (2002), Jones (2002). 
ser no mundo; ao fazê-lo, ela abre para possibilidades concretas de resistência, reforma e renovação"' (PEREIRA, 2017, p. 41). ${ }^{18}$

A figura de khôra remonta, assim, à possibilidade de acolhimento e abertura de um lugar em que possam ser inscritas singularidades e, na qual polarizações hão de ser gradativamente desmanchadas, pertençam elas a que ordem for: o outro e o eu, o ouvinte e o falante, o aluno e o professor. Khôra aduza esse não lugar na espacialidade performativa da pedagogia; registro topo-poético de in-determinação, in-diferença, não reconhecimento; o prefixo in aplicado à essas noções nos levam a perceber antes as nuances políticas de khôra do que propriamente sua negatividade, visto que inscreve o que não pode ser [d]escrito, o que não encontra determinação, mantendo ao fim e ao cabo sua absoluta e in-tangível in-diferença.

Uma pedagogia performativa pode ser tomada, nesse sentido, como uma pedagogia em khôra, marcada pela dissolução das categorias hegemonicamente constituídas, seja naquilo que conhecemos como pedagogia, seja na cultura em geral. Pensar a pedagogia performativa em khôra significa dizer que todo binarismo é passível de ser suspenso: professor-aluno; escola-casa; conhecimento-ignorância; prazer-trabalho, mas ainda, recolocadas em outras possibilidades especializadas. Tais possibilidades, entretanto, não nomeadas, não caracterizadas, visam justamente - nessa operação inominável - guardar o traço de anonimidade que khorra aloja e que é rechaçado pela pedagogia em geral.

É, assim, que a zona de in-diferenciação que caracteriza khôra - ainda que não se confunda com -, propõe à compreensão e mesmo à caracterização da pedagogia performativa uma maneira mais alargada de lhe circunscrever. Indiferenciar ou indiferenciado não é traço comum da pedagogia, ao contrário, como professores procuramos trabalhar em direção a uma diferenciação. O modo como compreendemos khôra sugere que a potência [de]criativa de toda pedagogia adjetivada como performativa assenta-se no que não se pode determinar. É próprio, aliás, da teoria da performance estar nesse espaço de resistência a toda determinação, a qualquer conceito ou palavra e refratária aos modos estáveis de dizer sobre.

Logo, khôra torna possível "uma apropriação da impropriedade como tal" (AGAMBEN, 2013a, p. 22), na ação pedagógica. Pensamos com ela um espaço para aquilo que não tem lugar na escola e a escola como um não lugar:

18 Ao mencionarmos pedagogia performativa em vez de pedagogia crítico-performativa, procuramos amplificar o escopo desse tipo de teorização no campo educacional, concentrando-nos na dimensão performativa da pedagogia; ao se extrair o qualitativo/propriedade crítico, supomos igualmente dissociar uma dada poética educacional de qualquer vinculação epistêmica e ideológica, a fim de manter a "natureza" aberta da abordagem em questão. 
para o fora de lugar, para o inaudito, para o impensado, para o escondido, para in-ominável; uma dimensão propriamente política, cuja "espacialidade esfumaçada" cria, como bem salienta Carlos Skliar, em seu texto Desobedecer a Linguagem (2014), acontecimentos; locus que nunca se dissipa e se oferece no aberto da vida ao compartilhamento, ao comum, à conversação (SKLIAR, 2014, p. 37); e acrescenta, "à exposição inédita frente aos olhos dos outros, da relação íntima e transbordante com a contingência, da fragilidade, do poder do imprevisível" (SKLIAR, 2014, p. 36).

Se a Escola é o lugar da de-nominação, na medida em que baseada em uma tradição modernista, a pedagogia performativa propõe distanciar-se de uma espécie de vontade furiosa, legiferante, de determinação intrínseca ao ato de-nominar, de confinamento do outro no discurso; trata-se de um espaço possível de comunicabilidade no qual a ética tem relação com os possíveis e, ainda, com o fora, com o incomunicável próprio da performance.

É a isso que khôra se refere. Assim como a pedagogia performativa, khôra se apresenta como sendo a principal aliada, a amiga mais confiável daquilo que acontece, espaço no qual o existente, o outro pode se aninhar, derramar-se; ela providencia, como pudemos observar com Platão, "uma localização a tudo quanto pertence ao devir" [52b] (PLATÃO, 2011, p. 138). A khôra consiste, em suma, num espaço de escuta que faz falar, de recebimento que doa e de acolhimento que desaloja; porquanto seja amiga, ela

se pronuncia por meio de uma linguagem marcada pela intensidade dos instantes e pela rejeição absoluta à proliferação de adjetivos que interpelam, acusam, difamam. Como se se tratasse de uma linguagem limpa, fruto de um olhar limpo numa duração sem fundo, que impede a passagem de todo julgamento e que abre as portas para uma hospitalidade sideral, sem impor condições (SKLIAR, 2014, p. 50).

Não causa surpresa, portanto, que khôra seja amiga de tantos nomes - mãe, ama, nutriz -, que procure com eles, como nos lembra sutil e delicadamente Giorgio Agamben (2013b, p. 51), "viver na intimidade de um ser estranho", não para dele se aproximar, "mas para manter o estranho, distante, e mesmo inaparente - tão inaparente que o seu nome o possa conter inteiro [...], não ser mais que o lugar sempre aberto, a luz inesgotável na qual esse ser único, essa coisa, permanece para sempre exposta e murada"; é assim, com efeito, que o filósofo italiano define a ideia do amor. \#maisamorporfavor. 


\section{REFERÊNCIAS}

ALEMAN, G. Constructing Gay Performances: regulating gay youth in a "gay friendly" high school. In: ALEXANDER, B. K; ANDERSON, G. L; GALLEGOS, B. P. (Ed.) Performance Theories in Education: power, pedagogy and the politics of identity. New Jersey: Lawrence Erlbaum Associates, Publishers, 2005, p.149-172.

AGAMBEN, G. Bartleby, ou da contingência. Tradução de Tomaz Tadeu. Belo Horizonte: Editora Autêntica, 2015a.

AGAMBEN, G. A potência do pensamento: ensaios e conferências. Belo Horizonte: Editora Autêntica, 2015b.

AGAMBEN, G. A comunidade que vem. Belo Horizonte: Editora Autêntica, 2013a.

AGAMBEN, G. Ideia da prosa. Belo Horizonte: Editora Autêntica, 2013 b.

ALEXANDER, B. K. Para analisar criticamente as interações pedagógicas como performance. In: PEREIRA, M. de A. (Org.). Performance e Educação: [des]territorializações pedagógicas. Santa Maria: UFSM, 2013. p. 59-94.

ANTELO, R. La comunità che viene: ontologia da potência. In: SEDLMAYER, S.; GUIMARÃES, C.; OTTE, G. (Org.) O comum e a experiência da linguagem. Belo Horizonte: Editora da UFMG, 2007. p. 29-49.

ARENDT, H. Origens do Totalitarismo. Tradução Roberto Raposo. São Paulo: Companhia das Letras, 1989.

ATTELL, K. Giorgio Agamben: beyond the threshold of deconstruction. New York: Fordham University Press, 2015.

BARRENTO, J. Limiares sobre Walter Benjamin. Florianópolis: Editora da UFSC, 2013.

BASZILLE, D. T. When public performances go awry: reading the dynamics of diversity through power, pedagogy, and protest on Campus. In: ALEXANDER, B. K; ANDERSON, G. L; GALLEGOS, B. P. (Ed.) Performance Theories in Education - power, pedagogy and the politics of identity. New Jersey: Lawrence Erlbaum Associates, Publishers, 2005. p. 127-148.

BENJAMIN, W. Origem do drama barroco alemão. São Paulo: Editora Brasiliense, 1984.

BENJAMIN, W. Rua de mão única. Obras Escolhidas II. São Paulo: Editora Brasiliense, 1987.

BENJAMIN, W. The Arcades Project. Translated by Howard Eiland and Kevin McLaughlin. Harvard: Belknap/Harvard University Press, 2002.

BINI, E. T. In: PLATÃO. Diálogos V: O banquete; Mênon (ou da virtude); Timeu; Crítias. Tradução, textos complementares e notas: Edson Bini. Bauru: Edipro, 2010. 
DÄLLENBACH, L. Le récit speculaire: essai sur la mise en abyme. Paris: Seuil, 1977. DERRIDA, J. Khôra. Tradução: Nícia Adan Bonatti. Campinas: Papirus, 1995.

DETIENNE, M. Les maîtres de vérité dans la Grèce archaïque. Paris: Le Livre de Poche, 2006.

GAGNEBIN, J. M. Limiar, aura e rememoração: ensaios sobre Walter Benjamin. São Paulo: Editora 34, 2014.

GINGRICH-PHILBROOK, C. The queer performance that will have been. In: STUCKY, N; WYMMER, C. (Ed.) Teaching Performance Studies. Illinois: Southern Illinois University Press, 2002. p. 69-84.

HANNAH, D. Event-space: performance space and spatial performativity. In: PITCHES, J.; POPAT, S. (Ed.) Performance perspectives: a critical introduction. London: Palgrave McMillan, 2011. p. 54-62.

ICLE, G.; BONATTO, M. T. Por uma Pedagogia Performativa: a escola como entrelugar para professores-performers e estudantes-performers. Caderno CEDES, Campinas, v. 37, n. 101, p. 7-28, abril, 2017. Disponível em: <http://dx.doi.org/10.1590/cc010132622017168674>. Acesso em: 25 set. 2017.

ICLE, G. Estudos da Presença: prolegômenos para a pesquisa das práticas performativas. Revista Brasileira de Estudos da Presença, v. 1, n. 1, p. 09-27, jun. 2011. Disponível em: $<$ http://dx.doi.org/10.1590/2237-266023682>. Acesso em: 11 out. 2017.

ICLE, G. Para apresentar a Performance à Educação. Educação \& Realidade, Porto Alegre: UFRGS, v. 35, n. 2, p. 11-22, maio/ago. 2010. Disponível em: <http://www.seer.ufrgs. br/index.php/educacaoerealidade/article/view/15861/9473>. Acesso em: 26 set. 2017.

JONES, J. L. Teaching in the borderlands. In: STUCKY, N; WYMMER, C. (Ed.) Teaching Performance Studies. Illinois: Southern Illinois University Press, 2002, p. 175-190.

LOPES, R. Introdução. In: PLATÃO. Timeu - Crítias. Tradução do grego, introdução e notas: Rodolfo Lopes. Coimbra: Editora da Universidade de Coimbra, 2011.

OTTE, G.; SEDLMAYER, S.; CORNELSEN, E. (Org.) Limiares e Passagens em Walter Benjamin. Belo Horizonte: Editora UFMG, 2010.

PEREIRA, M. de A. Pedagogia crítico-performativa: tensionamentos entre o próprio e o comum no espaço-tempo escolar. Caderno CEDES, Campinas, v. 37, n. 101, p. 2944, abr. 2017. Disponível em: <http://dx.doi.org/10.1590/cc0101-32622017168666>. Acesso em: 25 set. 2017.

PEREIRA, M. de A. Performance docente: sentidos e implicações pedagógicas. In: PEREIRA, M. de A. (Org.). Performance e Educação: [des]territorializações pedagógicas. Santa Maria: UFSM, 2013, p. 23-36.

PEREIRA, M. de A. Performance e educação: relações, significados e contextos de investigação. Educação em Revista. Belo Horizonte, v. 28, n. 1, p. 289-312, mar. 2012. 
Disponível em: $<$ http://dx.doi.org/10.1590/S0102-46982012000100013>. Acesso em: 21 set. 2017.

PEREIRA, M. de A. Pedagogia da Performance: do uso poético da palavra na prática educativa. Educação \& Realidade, Porto Alegre: UFRGS, v. 35, n. 2, p. 139-156, maio/ ago. 2010. Disponível em: <http://www.seer.ufrgs.br/index.php/educacaoerealidade/ article/view/11084/9448>. Acesso em: 26 set. 2017.

PLATÃO. Timeu - Crítias. Tradução do grego, introdução e notas: Rodolfo Lopes. Coimbra: Editora da Universidade de Coimbra, 2011.

PLATÃO. Diálogos V: O banquete; Mênon (ou da virtude); Timeu; Crítias. Tradução, textos complementares e notas: Edson Bini. Bauru: Edipro, 2010.

RANCIÈRE, J. A partilha do sensivel: estética e política. São Paulo: Exo Experimental, 2005.

SEDLMAYER, S.; GUIMARÃES, C.; OTTE, G. (Org.) O comum e a experiência da linguagem. Belo Horizonte: Editora da UFMG, 2007.

SKLIAR, C. Desobedecer a Linguagem: educar. Belo Horizonte: Editora Autêntica, 2014.

URRIETA JÚNIOR, L. "Playing the game" versus "selling out": chicanas and chicanos relationship to whitestream schools. In: ALEXANDER, B. K; ANDERSON, G. L; GALLEGOS, B. P. (Ed.) Performance Theories in Education: power, pedagogy and the politics of identity. New Jersey: Lawrence Erlbaum Associates, Publishers, 2005, p. 173-198.

WARREN, J. T. Bodily excess and the desire for absence: whiteness and the making of (raced) educational subjectivities. In: ALEXANDER, B.K; ANDERSON, G. L; GALLEGOS, B.P. (Ed.) Performance Theories in Education - power, pedagogy and the politics of identity. New Jersey: Lawrence Erlbaum Associates, Publishers, 2005, p. 83-106.

Texto recebido em 29 de outubro de 2017. Texto aprovado em 31 de outubro de 2017. 
